\title{
Effect of Framing and Locus of Control on Commitment Escalation in Investment Decisions
}

\author{
Linda Arisanty Razak ${ }^{1}$, Haliah$^{2}$, Hamid Habbe ${ }^{3}$, Mediaty ${ }^{4}$ and Arifuddin 5 \\ ${ }^{1}$ University of Muhammadiyah Makassar, e-mail: lindarazak@unismuh.ac.id \\ ${ }^{2}$ University of Hasanuddin \\ ${ }^{3}$ University of Hasanuddin \\ ${ }^{4}$ University of Hasanuddin \\ ${ }^{5}$ University of Hasanuddin
}

\begin{abstract}
This research aimed to examine whether framing and locus of control affect the commitment escalation in making investment decisions. This research was an experimental study by applying a design of factorial $2 \times 2$ between subjects with a sample of 84 students at the University of Muhammadiyah Makassar. Test Analysis in this study used Two Way ANOVA. The results of this study proved that framing affects the commitment escalation in decision making. This means that managers tend to escalate commitments when the information in the frame with negative framing and tend not to continue the commitment escalation when the information is framed with positive framing. Locus of control variable has no effect on the commitment escalation in decision making. Individuals only give attention to the outcome distribution made by the company, that is, it is fair to be perceived in accordance with the sacrifices incurred by individuals. This will affect the level of commitment escalation held by individuals towards the company.
\end{abstract}

Keywords: framing, locus of control, commitment escalation

\section{Introduction}

Decision making is often equated with the process of thinking, managing, and problem solving. In organizational setting, decision making is often defined as the process of choosing among various alternative actions that affect the future. According to Kahneman and Tversky (1986), decision is defined as actions or options between which must be chosen, consequence of action and conditional probabilities or contingencies that relate to the results of actions.

In particular, this research empirically examines how management's behavior towards the commitment escalation in decision making which is related to the framing of information and the locus of control, namely the existence of self-control behavior that exists in individuals when faced with decision making.

Framing is related to how an individual feel or structures a decision. Gasiaswaty (2009) states that framing is closely related to reference points, which is a point used as a benchmark in comparison. In framing term, this reference point becomes someone's frame in considering a possibility. The possibility that has been framed is then evaluated by the decision makers.

In the context of decisions on investment that indicate failure, the sunk cost acts as the manager's reference point in making decisions. The fact that investment that shows a negative prospect leads to several possibilities including loss/profit that is certain to occur and the possibility of profit/loss in the future that is less certain. When the possibilities are framed positively, the profit information will be more highlighted. When these possibilities are framed negatively, information about losses will be highlighted.

Bateman and Zetihaml in Koroy (2008) state that when information is presented in a negative decision frame, decision makers tend to seek risk by continuing the project. While information is presented in a positive frame, decision makers tend not to take risks by not continuing the project.

Nevertheless, various empirical evidences that have been obtained show that managers who start a project which then becomes unprofitable are more likely to continue the project than managers who do not start the project (Staw, 1976, 1981). The behavior of these decision makers is often referred to 
as the commitment escalation. The commitment escalation refers to the tendency of decision makers to survive or escalate their commitment to a series of failed actions (Brockner, 1992). Bazerman (1994) defines escalation as irrational (nonrational commitment escalation) that is the degree to which an individual' deviates a commitment to certain actions carried out previously to a point that passes through a rational decision-making model. Individuals or managers generally have difficulties in separating decisions taken previously with decisions related to the future. As a consequence, individuals will tend to refract their decisions because of past actions and have tendency to escalate commitments especially when receiving negative feedback (Bazerman, 1994).

Various researches have been conducted to explain this escalation behavior. Brockner (1992) suggests that there are three theories that can explain this escalation, namely the theory of self-justification, prospect theory (Kahneman and Tversky, 1979, 1981) and decision dilemmas theory. These three theories are based on the affective aspect or from the psychological side of the decision makers.

This research attempts to clarify the explanatory power of one of the above theories, the prospect theory as a determinant of the commitment escalation. In line with Brockner's (1992) idea, this research argues that prospect theory cannot fully explain the causes of commitment escalation. More specifically, the prospect theory can explain escalation depending on certain conditions in decision making. These conditions also include personal attributes of decision makers.

One of the few personal attributes that are relevant is locus of control. Locus of control is an individual's control over his/her work and his/her trust in self-efficacy (Tsui and Gul, 1996). There are 2 types of locus of control according to Tsui and Gul (1996) namely; internal locus of control and external locus of control. Internal locus of control is someone who believes that success comes from his/her inner abilities, while external locus of control is someone who believes that success is determined by others, destiny, and other factors outside of him/herself.

Managers who have an external locus of control type tend to have a high level of sensitivity, while managers who have an internal locus of control type tend to have a low level of sensitivity (Irfan: 2010), so if a manager has a high level of sensitivity, it tends to decrease the level of commitment escalation, and vice versa if a manager has a low level of sensitivity, it tends to increase the level of his/her commitment escalation.

This study took students as sample, although the general commitment escalation in the real world is carried out by decision makers, namely managers. Most experimental studies regarding the commitment escalation use undergraduate students as surrogates of managers who have experienced. The use of these inexperienced students as subjects raises doubts about their accuracy as substitutes or surrogates of experienced managers (Chang et.all, 2010). This doubt also arises over the generalization of the results of research conducted. Prospect theories such as those proposed by Tversky and Kahneman (1979) are based on their experiments on students. Likewise, the argument that supports the prospect theory as a determinant of the commitment escalation as an example is based on Whyte's (1993) research that used students as experimental subjects. Although some researchers have researched and proven it in experienced subjects (for example Rutledge and Harrell, 1993), but so far it is unclear whether prospect theory also applies universally, so it leads to a commitment escalation.

Based on previous empirical theories and researches, the formulation of the question that then arises is whether the framing and locus of control can affect the commitment escalation in decision making? This question is an interesting issue to investigate because it still requires a more detailed explanation and broader empirical evidences.

Prospect Theory. Kahneman and Tversky $(1979,1981)$ investigated the irregularities and contradictions of human behavior, when subjects were offered a particular formulated/framed choice, it might conduct risk aversion, but when the subjects were offered something that had the same essence and was formulated/framed differently, it might show risk seeking behavior/attitude. The most important essences of research by Kahneman and Tversky reveal that people's behavior in making decisions related to profits is quite different from people's behavior in making decisions 
related to losses. For example, in a condition of uncertainty, someone is faced with an alternative option that is equally beneficial, the first is an alternative choice that is definitely profitable but the profit is smaller than the second choice, while the second is an alternative that is likely not to obtain greater profits with a probability of $50 \%$, a person will tend to choose the first alternative that is definitely profitable. This illustrates the risk aversion attitude.

Conversely, in conditions of uncertainty, a person is faced with an alternative choice that is equally detrimental to the first, which is an alternative choice, is definitely detrimental and the second is an alternative choice, the possibility of no loss, or the possibility of loss, but greater with a probability of $50 \%$. The second is the possibility of no loss or a greater probability of loss with a $50 \%$ probability. This illustrates the attitude of risk acceptance/risk seeking (Kahneman and Tversky, 1979). Therefore, with the prospect theory approach, commitment escalation occurs because the individual is responsible for the initial decision of a series of investments, with the evidence that the investment performance has deteriorated, tends to be more daring to take risks which are manifested in the next stage of investment in the hope that the next investment performance is profitable and can cover the previous performance decline (Brockner, 1992).

Framing. Framing is the way a fact or information is revealed (Tversky and Kahneman 1979; Rutledge and Harrel, 1995). Information framing can affect a person in decision making. When there are uncertainty conditions, information framing has a significant impact on decision making (Handoko; 2008). When a problem is same, but it is framed in conditions: "perceived gain" and "perceived loss", it will be responded differently by decision makers (Bazerman; 1994). In prospect theory, the way someone frames a "problem" dramatically can change the perceived natural point of a question. Decision makers tend to avoid the risk when an outcome is expressed as gains and avoid risks when an outcome is expressed as losses. Framing is related to the decisions taken (Kahneman and Tversky; 1981). Research subjects showed different behaviors when information was presented in a different way (positive and negative).

The theory used in examining the bias due to framing is the prospect theory which suggests that the frame adopted by a person can influence his/her decision. In this case, when a decision maker is given an alternative decision which is framed positively, the decisions taken will tend to be risk averse. Whereas when information is presented negatively, the decisions taken will tend to be risk seeking. The bias that occurs due to information framing can make decisions taken to be not optimal because the information frame affects risk preferences by decision makers.

Locus of Control. Locus of Control is defined as the extent to which a person feels a contingency relationship between actions and the results that they obtain (Tsui and Gul 1996). Locus of control is the way of a person views an event whether he/she can or cannot control the events that occur to him/her (Irfan, 2010).

According to Tsui and Gul (1996), Locus of Control is divided into two parts, namely the internal Locus of Control and the external Locus of Control, if someone believes that he/she has the ability to control his/her destiny, it is called the internal Locus of Control. In this case, he/she believes that control lies within him/herself. Whereas the external Locus of Control refers to people who believe that the results they get are determined by extrinsic conditions or outside themselves. For example, by fate, luck. Irfan (2010) reveals the different commitment escalation in sensitizer and repressor individual and individual who has internal locus of control and external locus of control. The results reveal that individual who is repressor tends to experience greater escalation than individual who is sensitizers, as well as individuals who tend to have internal locus of control tend to experience greater escalation than individuals who tend to be locus of external. Locus of control in this study is grouped by using The Work Locus of Control (WLCS) developed by Spector (1988) consisting of 12 questions. People who tend to be internal locus of control will have confidence that what happens to them is the result of their own efforts. Whereas people with external locus of control tend to see what happens in their lives is a fortune or believes in the existence of external factors that control their lives. 
Commitment Escalation. The commitment escalation is a commitment that someone decides to continue an investment, even though the investment is harmful or not profitable. Commitment escalation is also called nonrational escalation of commitment (Bazerman; 1994). The commitment escalation is a series of actions or behaviors of individual, group or organization that tend to decide to allocate a greater source of funds to subsequent investment projects, although there is information of declining investment performance (Staw, 1976, Ros 1978; Ross and Staw, 1986).

The framework that uses prospect theory focuses its analysis on how information is presented and processing. In prospect theory, each decision is made after the information is first filtered through "decision frame" by decision makers (Kahneman and Tversky, 1979).

Kreitner and Kinicki (2005: 23-26) mention four factors that led to the behavior of the commitment escalation, namely: psychological and social factors, organizational factors, project characteristics, and contextual factors. Psychological and social factors are the main contributors to the commitment escalation which includes the ego defense and individual motivation. Someone who has ego defense character and individual motivation then he/she tends to refract the facts that he/she receives so he/she will tend to support the decisions made previously.

Hypotheses Development. Framing is how information or facts are revealed. Kahneman and Tversky (1981) state that framing is related to decisions taken. Meanwhile, the commitment escalation is a commitment of someone to decide to continue an investment, even though the investment is harmful or not profitable. When a decision maker is given an alternative decision framed positively, the decisions taken will tend to be risk averse or avoid risk. Whereas when information is presented negatively, the decisions taken will tend to be risk seeking, therefore, the first hypothesis was formulated as follows:

H1: Decisions framed positively or negatively tend to affect someone towards the commitment escalation.

Locus of control is an individual's control over his/her work and belief in self-efficacy (Rotter, 1996). The manager who has the internal locus of control believes that an event is always under his/her control and will always take roles and responsibilities in determining right or wrong so that he/she tends to escalate his/her commitment because he/she feels that he/she has responsibility for the project that has been carried out and expects improvements with additional funds. Besides that, it is also to maintain the good reputation and his/her external trust. While the manager who is an external locus of control tends to see what happens in his/her life is no more than a fortune or believes in the existence of external factors that control his/her life.

The prospect theory proposed by Kahneman and Tversky (1981) explains that under conditions of uncertainty, someone is faced with alternative choices that provide the same benefits. The first is an alternative choice that is definitely profitable, but it is smaller than the second choice. Whereas the second option is an alternative choice that is likely not to get a bigger profit with a probability of $50 \%$, then someone tends to choose the first alternative that is definitely profitable. Factors that affect locus of control are age, experience of success and failure, and the environment affects the locus of control that they have. The more experience that possessed by an individual can increase the amount of confidence in his/herself in the process of achieving the goals to be achieved, whereas the less experience that possessed by an individual can weaken someone's confidence in achieving his/her goals. Environmental factors also play a great role to an individual, for example if an individual has colleagues who have great enthusiasm and confidence, then he/she will be affected to have the confidence and enthusiasm of his/her colleagues.

$\mathrm{H} 2$ : Locus of control tends to affect someone towards the commitment escalation.

\section{Research Methodology}

A total of 90 students of Accounting Department of the University of Muhammadiyah Makassar, in academic year 2015 who have taken management accounting and financial management courses were chosen as research participants. In this study, they were projected as project managers in Airlines 
Company. But only 84 students could be taken in this study after the selection process. In the experimental stage, the demographic characteristics data of participants showed that students who participated in this study consisted of 45 women and 39 men.

This research consisted of the variable of framing and Locus of Control, as well as the Commitment Escalation. This study was designed in an experimental form with the aim to determine the tendency of decision-making behavior on investment projects that indicate failure. In this case, students were the surrogate decision makers (managers). This experimental research was conducted to find out whether Framing and locus of control affect the Commitment Escalation in investment decisions making. Experiments in this study were manipulated with framing conditions and locus of control with factorial experimental design 2 × 2 between subjects.

Participants who received case 1 were given a positive framing treatment, participants who received case 2 were given a negative framing treatment and the third participant was given a locus of control questionnaire. In this study, it was also conducted randomized the treatment conditions to reduce the effect of variables that could interfere with the validity of research results. Randomization in this study was each respondent gets a treatment from the possibility of a combination of positive and negative framing cases given in 2 case versions. The distribution of cases was distributed in the same number of each instrument and was expected to produce the same number of respondents for each treatment combination.

In this research, the dependent variable was the commitment escalation which was measured by asking participants to make investment decisions. The decisions consisted of the decisions to stop projects 1-5 and the decision to continue the project 6-10.

The first independent variable was framing, for positive framing in this study was proxied by presenting information about definite benefits and negative framing by presenting information about definite losses. The instrument used case adaptation from Rutledge (1995). This study took the case vignette with negative and positive framing conditions from Rutledge (1995). Measurement of positive framing was given a score of 1 while for negative was given a score of 2 .

The second independent variable was Locus of control, by using 5 points Likert scale. Locus of control in the study was grouped by using The Work Locus of Control (WLCS) developed by Spector (1988) consisting of 12 questions. For measuring the type of locus of control variable was to see the mean score. Internal locus of control was indicated by the value of the smaller participants' answers. Experiments are designed in stages that must be conducted by participants. There were 4 stages as follows:

1) Participant Data Filling Stage. At this stage, participants filled in their personal data in the form of name, semester taken, GPA, and gender.

2) Treatment stage. At this stage, participants were divided into three groups and each group was given a different case, the first group was given cases related to framing by using two cases, namely the first case with positive framing, and the second case was negative framing. These cases manipulated participants as financial managers of a Sriwijaya Air as a company that invested in new flights. Participants as financial managers took the decision to invest or not on the new flight path. Participants made decision to invest in opening a new flight line. The investment that has been issued in the past 12 months was IDR 4 billion. The value of this investment represented a quarter of the company's investment in research and development projects. The latest information stated that one of the company's competitors had just launched the same investment that the investment had done and had many advantages in various ways compared to the investments made by the company. This makes the company's investment (investment X) less superior to competitors and causes an investment of IDR 4 billion to be worthless. As a result of the presence of this competitor's product, this Investment X would endanger the company's finances in the next years. But this situation might be improved by investing an additional investment of IDR 2 billion. This additional investment was useful in increasing some of the weaknesses in new investments being developed. If you decided to 
invest IDR 2 billion in investment $X$, then there were two possibilities that occur, i.e., a product worth IDR 6 billion would be produced (so that it could return the original IDR 4 billion plus an additional investment of IDR 2 billion) or the product remains unsuccessful (or not valuable). Participants were given the option to continue the investment project or stop the investment. And the second group was given the third case, participants were given a questionnaire to measure Locus of Control for each participant based on the Spector instrument using 12 question items. This stage determined the participants' Locus of Control level so that participants had high Locus of Control (Internal Locus of Control), and participants had low Locus of Control (External Locus of Control).

3) Decision Making Stage. At this stage, the researcher asked participants to choose between two options to increase investment or not increase investment in new flight paths. Participants were also asked to determine the level of confidence in the options that they chose. This level of confidence was written by giving an arbitrary scale sign of the choice of strongly uncertain and strongly confident. To stop the project was given a scale of 1-5 and to continue the project was given a scale of 6-10.

4) Manipulation Check Stage. Manipulation check consisted of two questions. Participants were asked to answer correctly or incorrectly the statements given in these questions. The problem of manipulation check was a control over the answers given by the participants which showed how far the level of participants' understanding towards the cases or treatments was given.

The data analysis method used in this experiment design was Two Way analysis of variance (ANOVA) to test the overall effect of framing and locus of control on the commitment escalation. Before testing the hypothesis, the instrument validity was tested first by using factor analysis and reliability testing with Cronbach alpha, and the homogeneity testing whether the population variant was the same or not. Homogeneity test was conducted as a prerequisite test before conducting analysis of variance test.

\section{Result and Discussion}

Based on Table 1, in descriptive statistics, the average value of the commitment escalation was 46.75 . The minimum data value was 37 and the maximum value of the data was 56 . The result of the standard deviation showed that 4,191 which are lower than the average value of 46.75 , this indicated that the data deviation was low so that the data distribution was normal.

Table 1. Descriptive statistics

\begin{tabular}{|c|c|c|c|}
\hline & $\begin{array}{l}\text { Escalation of } \\
\text { Commitment }\end{array}$ & Framing & Locusofcontrol \\
\hline Valid & 84 & 84 & 84 \\
\hline Missing & 0 & 0 & 0 \\
\hline Mean & 46.75 & 1.50 & 1.67 \\
\hline Std. Deviation & 4.191 & .503 & .474 \\
\hline Minimum & 37 & 1 & 1 \\
\hline Maximum & 56 & 2 & 2 \\
\hline
\end{tabular}

The result of the calculation of the validity test showed that the questions in the overall variable were valid and feasible to be used to indicate the extent to which the score/value/size obtained actually stated the measurement/observation to be measured. Based on the reliability test result, the Cronbach alpha score showed a value of 0.562 . 
Table 2. Reliability Statistics

Cronbach's Alpha

$\mathrm{N}$ of Items

562

The result of the Levene test showed that the subjects' Levene's test in this study were not significant and greater than p-value 0.05 , so that the population in the subject had the same variance.

This result indicated that there was no significant variance difference between these data groups. It can be concluded that the homogeneity assumption of variance which is an assumption of variance analysis requirements is fulfilled and can be continued to ANOVA test.

Table 3. Levene's Test of Equality of Error Variances ${ }^{\mathrm{a}}$ (Independent Variable: commitment escalation)

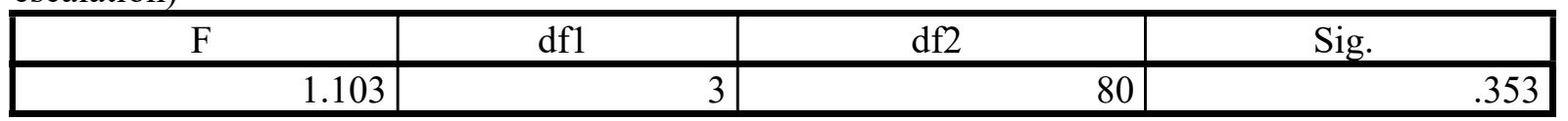

Tests the null hypothesis that the error variance of the dependent variable is equal across groups.

a. Design: Intercept + Framing + Locus

Data analysis technique used to test hypotheses in this study used two ways ANOVA models. Two ways ANOVA was used to test two independent variables with two categories. The significance level used in this study was 0.05 . To see the significance of research testing results, it can be seen from the $\mathrm{p}$-value of data processing results. If the significance $\mathrm{p}$-value is $\leq 0.05$, then the hypothesis is accepted. Meanwhile, if the p-value is $>0.05$, then the hypothesis is rejected.

Table 4. ANOVA Two Way Tests of Between-Subjects Effects (Dependent Variable: commitment escalation)

\begin{tabular}{|l|r|r|r|r|r|}
\hline Source & Type III Sum of Squares & Df & Mean Square & \multicolumn{1}{|c|}{ F } & Sig. \\
\hline Corrected Model & $351.574^{\mathrm{a}}$ & 3 & 117.191 & 8.475 & .000 \\
Intercept & 161909.403 & 1 & 161909.403 & 11709.483 & .000 \\
Framing & 283.292 & 1 & 283.292 & 20.488 & .000 \\
Locus & 7. dan371 & 1 & 7.371 & .533 & .467 \\
Error & 1106.176 & 80 & 13.827 & & \\
Total & 185045.000 & 84 & & & \\
Corrected Total & 1457.750 & 83 & & & \\
\hline
\end{tabular}

a. R Squared $=.241$ (Adjusted R Squared $=.213$ )

ANOVA test result indicated that there was a direct effect of framing on the commitment escalation. This can be seen from the F score, i.e., 20,488 and significant at $p=0.000$, this means that management tends to escalate commitment when the information in the frame with negative framing and tends not to continue the commitment escalation when the information was framed with positive framing. While the locus of control variable did not have a direct influence on the commitment escalation. This can be seen from the F score, i.e., 0.533 at $\mathrm{p}=0.467$.

The test results above proved that framing has a positive effect on the commitment escalation; it means that information presented in both positive and negative forms can affect managers in making decisions. This means that the information presented positively can reduce the commitment escalation behavior of managers, whereas if information is presented negatively then managers tend to escalate more.

From the data above, it can be concluded that the first hypothesis was accepted, namely decisions that are framed positively or negatively tend to affect someone towards the commitment escalation. The results of this study were supported by research conducted by Susanto (2011) which showed that 
information framing affects the nature of decisions taken. The results of this study also supported the research conducted by Bahrudin and Anissa (2011) which also state that if information is presented in a negative framing, then the tendency of a manager to escalate commitment is greater.

But the results of the study were different from research carried out by Amril Arifin (2004) which states that when decision information cannot be simplified or when decision information is presented in gain-domain/negative-frame and loss-domain/positive-frame, the effect of framing does not significantly affect participant's decision-making. The level of preference for risk possessed by decision makers on positive frames and negative frames has the same level so that the decision making is not different.

This study supports the prospect theory developed by Kahneman and Tversky (1981) which is able to explain how a frame adopted by a person can influence his/her decisions. In this case, when a decision maker is given an alternative decision framed positively, the decision will tend to be risk averse, whereas when the information is presented negatively, the decision taken tends to be risk seeking.

The test results in the second hypothesis proved that the locus of control has no effect towards someone in conducting a commitment escalation, or in this case, the second hypothesis was rejected. Locus of control did not affect a person's behavior in committing a commitment escalation, because of the balance between input sacrificed by the individual and the outcome to be received (Adam; 1965). Individual only pays attention to the distribution of outcomes carried out by the company that is fair to be felt in accordance with the sacrifices incurred by individual. This will affect the level of commitment escalation held by individual towards the company

The results of this study were supported by the results of Irfan's research (2010) which showed that the locus of control factor possessed by a manager in determining whether or not an action taken by a company did not affect the level of commitment escalation due to the company but the results of this test were different from the results of Endah Suwarni's research (2011) which showed that individual with internal locus of control was more likely to increase or invest than individual with external locus of control in negative framing conditions.

\section{Conclusion}

This research examined the effect of framing and locus of control on the commitment escalation. The finding of the framing affects the commitment escalation in the investment decision making, this means that information presented in both positive and negative forms can affect a manager in making decisions. The prospect theory explains how a frame adopted by a person can influence his/her decision. In this case, when a decision maker is given an alternative decision that is framed positively then the decision taken will tend to avoid risk (risk averse) while when the information is presented negatively then the decision taken tends to take risks (risk seeking).

The finding of the locus of control variable has no effect on the commitment escalation in making investment decisions, these results indicate that individual only pays attention to the distribution of outcomes made by the company to be fairly perceived in accordance with the sacrifices incurred by individual. This will affect the level of commitment escalation held by individual towards the company.

Some things related to this research consist of this research is an experimental research, where the task given to participants is a simplification of the task of an investment that was conducted. Therefore, the job description does not include all the information considered in the actual investment situation. The suggestion for further researchers is to examine this problem, namely when the organization and managers have difficulty in returning expectations when the investment returns and falling below the desired rate of return. 


\section{References}

Adams, J. S. (1965). Inequity in social exchange. In Advances in experimental social psychology (Vol. 2, pp. 267-299). Academic Press.

Andi Irfan, (2010). The Effect of Locus of Control towards the Relationship Between Justice and Commitment Escalation Level in Capital Budgeting. National Symposium on Accounting XIII Purwokerto.

Arifin, A. (2004). Effect of Framing on managerial accounting decisions in individual-group perspectives: Test on Prospect Theory and Fuzzy-Trace Theory (Doctoral dissertation, Gadjah Mada University).

Bahrudin, S., \& N. Anissa. (2011). Testing the Effect of Framing and Locus of Control as Commitment Escalation Determinant in Investment Decision. STIE BPD Jateng, Prestasi, 7 (1).

Bazerman, M.H. 1994. Judgment in Managerial Decision Making, 3rd ed., New York, NY: Wiley.

Brockner, J. (1992). The escalation of commitment to a failing course of action: Toward theoretical progress. Academy of management Review, 17(1), 39-61.

Chong, V. K., \&Syarifuddin, I. (2010). Escalation of commitment to unprofitable projects: An experimental investigation of the effect of conformity pressure and self-esteem. Accounting, Accountability \& Performance, 16(1/2), 1.

Harrell, A. dan P. Harrison. (1994). An incentive to shirk, privately held information, and managers' project evaluation decisions. Accounting, Organizations and Society, 19: 569-577.

Grasiaswaty, Novika, 2009, The Framing Phenomenon behind Big Discounts, http: //ruangpsikologi.com, accessed on 25 May 2018.

Kahneman, D. dan A. Tversky. (1979). Prospect theory: an analysis of decisions under risk. Econometrica, 47: 263-291.

business, S251-S278.

(1986). Rational choice and the framing of decisions. Journal of Science, 211 (30): 453-458.

Kreitner, Robert \& Kinicki, Angelo. (2005). Organizational behavior. Edition 5. (Interchangeable: ErlySuandy). Jakarta: Salemba Four.

Kanodia, C., R. Bushman dan J. Dickhaut. (1989). Escalation errors and the sunk cost effect: an explanation based on reputation and information asymmetries. Journal of Accounting Research, 27: $59-77$.

Koroy, T. R. (2008). Frame Effect Testing as Commitment Escalation Determinant in Investment Decision: Impact of Work Experience. National Symposium on Accounting XI.

Neuman, W. L. (2013). Social research methods: Qualitative and quantitative approaches. Pearson education.

Rutledge, R. (1995). Escalation of commitment in groups and the moderating effects of information framing. Journal of Applied Business Research,11:17-22.

and Harrell, A. (1993). Escalating commitment to an ongoing project: the effects of responsibility and the framing of accounting information. International Journal of Management, 10 (3): 300-313.

Susanto, B., \&Mashar, R. (2011). Intrinsic Motivation and Framing Budget Information in Investment Decision Making: Comparison of Individual and Group Decisions. Journal of Economic Business Analysis, 9 (1), 27-38.

Sekaran, U., \& Bougie, R. (2016). Research methods for business: A skill building approach. John Wiley \& Sons.

Suwarni, E., Subroto, B., \&Irianto, G. (2011). Commitment Escalation and De-escalation to Individual with Internal Characteristics of Locus of Control in Gradual Investment Cases. National Symposium on Accounting XIV Aceh, 
Spector, P. E. (1988). Development of the work locus of control scale. Journal of Occupational and Organizational Psychology, 61(4), 335-340.

Staw, B. M. (1976). Knee-deep in the big muddy: A study of escalating commitment to a chosen course of action. Organizational behavior and human performance, 16(1), 27-44.

Staw, B. M., Sandelands, L. E., \& Dutton, J. E. (1981). Threat rigidity effects in organizational behavior: A multilevel analysis. Administrative science quarterly, 501-524.

Tsui, J. S., \& Gul, F. A. (1996). Auditors' behavior in an audit conflict situation: A research note on the role of locus of control and ethical reasoning. Accounting, Organizations and Society, 21(1), 41-51. 